RAD Conference Proceedings, vol. 3, pp. 119-122, 2018

ISSN 2466-4626 (online) | DOI: 10.21175/RadProc.2018.26

www.rad-proceedings.org

\title{
RADON EXHALATION RATE OF SOME BUILDING MATERIALS COMMON IN SERBIA
}

\author{
Dragan Avramović ${ }^{1}$, Igor Čelikovićc ${ }^{*}$, Predrag Ujić ${ }^{1}$, Ivana Vukanac1, \\ Aleksandar Kandić ${ }^{1}$, Aleksandar Jevremović ${ }^{1}$, Dunja Antonijeviććn, Boris Lončar²
}

1"Vinča” Institute of Nuclear Sciences, University of Belgrade, Belgrade, Serbia

${ }^{2}$ Faculty of Technology and Metallurgy, University of Belgrade, Belgrade, Serbia

\begin{abstract}
It is well-known that radon is the second important human carcinogen for lung cancer, after smoking. The major sources of indoor radon concentrations are soil and building material. Under certain conditions, a dose received from the inhalation of radon and its progenies can be higher than a dose received from the external exposure due to radium concentration in building materials. In this contribution, the results of the radon and thoron exhalation rate measurement from 9 commonly used building materials are reported. Exhalation rate measurements were performed with accumulation chamber method using active device for measurement of radon concentration.
\end{abstract}

Key words: Radon, thoron, exhalation rate measurement, building material

\section{INTRODUCTION}

Radon is a noble, naturally occurring radioactive gas and with its progenies it contributes with more than $50 \%$ to annual dose received from ionizing radiation [1]. Based on the recent epidemiological studies, World Health Organization has recognized radon as a second leading cause of lung cancer, after smoking, being responsible for between $3 \%$ and $14 \%$ of all lung cancers [2].

Being a member of natural ${ }^{238} \mathrm{U}$ decay chain, higher concentrations of radon in houses are expected in regions having higher content of ${ }^{238} \mathrm{U}$ and ${ }^{226} \mathrm{Ra}$ in underlying rocks and soils. The highest radon concentration is in mineral grains, where it origins from, and is of the order of $\mathrm{MBq} \mathrm{m}^{-3}$. Depending on the emanation factor, radon leaves the grains reaching the soil gas where concentration is typically of the order of $10^{4-10^{5}} \mathrm{~Bq} \mathrm{~m}^{-3}$ [3]. Radon further migrates by means of diffusion and advection toward shallow environment decreasing in its concentration. Finally, it reaches the atmosphere and at $1 \mathrm{~m}$ height from the ground, worldwide average radon concentration is 4 $\mathrm{Bq} \mathrm{m}^{-3}$ [2]. By building a house, the soil gas tends to enter the house due to pressure-driven flow caused by difference in temperature between air in house and soil. Typically, $1 \%$ of indoor air originates from the soil gas and the rest comes from outdoors. In the case of houses with cracks in foundations, built on the highly permeable soil, more than $10 \%$ of indoor air can originate from the soil gas, reaching therefore high indoor radon concentrations [3].

The second most important source of indoor radon, after the soil beneath a building is building material. In recent years, an indoor air quality becomes an important issue, especially in densely populated area. New materials and trends are being introduced in the civil engineering, leading to building with better thermal insulations, construction of doors and windows that are more and more tight. As a consequence, an air exchange rate is decreasing, leading to an increase of indoor radon concentration [4].

Under certain conditions in dwellings with very low air exchange rate of $0.2 \mathrm{~h}^{-1}$, a dose received due to inhalation of radon and its progenies, can be higher than a dose received from the external exposure to ${ }^{226} \mathrm{Ra}$ concentration in building material [5].

Although it is not mandatory to control radon exhalation rate from building materials, it is important, due to abovementioned arguments, to better understand and estimate its contribution to the dose. Thus, the growing interest in the development of the exhalation rate methods and its measurements [6], [7] is not surprising.

In this paper, the results of the radon (referred to ${ }^{222} \mathrm{Rn}$ ) and thoron (referred to ${ }^{220} \mathrm{Rn}$ ) exhalation rate measurements from common building material used for the construction of houses are presented. Activity concentration of ${ }^{226} \mathrm{Ra}$ and ${ }^{232} \mathrm{Th}$ were measured as well, since they are predecessors of radon and thoron, respectively. Since the radon exhalation rate depends not only on Ra content in building material, but on the porosity of the material, moisture content we also report on the investigation of the radon exhalation rate as a function of particle size and moisture content of the selected building materials.

*icelikovic@vin.bg.ac.rs 


\section{MATERIALS AND METHODS}

\subsection{Sample preparation}

The exhalation rate of different building material was measured. In total, 9 different building materials were analyzed, consisting mainly of the most commonly used ones, based on clay or concrete. Several building materials with improved thermal isolation characteristics, that in recent years are becoming more common due to the increased awareness on energy saving policies, were also analyzed. The exhalation rates of some decorative materials were analyzed as well. In addition, one bedrock with high ${ }^{226} \mathrm{Ra}$ content is also analyzed.

All samples were crushed, dried at $70-80{ }^{\circ} \mathrm{C}$ and sorted using sieves with different sizes of the pores. For gamma spectrometric measurements and radon exhalation rate measurements, samples with diameter of particles less than $0.5 \mathrm{~mm}$ were used.

\subsection{Gamma spectrometric analysis}

Gamma spectrometric measurements were performed using coaxial HPGe detector model GX5019, from Canberra $\AA$, with $55.1 \%$ of relative efficiency and with resolution of FWHM=1.75 keV for $1332.5 \mathrm{keV}$ energy of ${ }^{\circ} \mathrm{Co}$. The efficiency and energy calibration was performed using soil matrix spiked with the common mixture of gamma emitters certified by the Czech Metrological Institute. The activity concentration of ${ }^{226} \mathrm{Ra}$ in building material samples were determined by analyzing full energy peak of $186.21 \mathrm{keV}$ gamma line. In the case of presence of ${ }^{235 \mathrm{U}}$ in spectra $(185.72 \mathrm{keV})$, activity concentration of

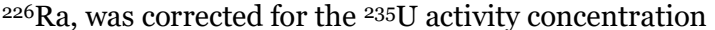
estimated by measuring $235 \mathrm{U}$ photopeak at $143.77 \mathrm{keV}$ [8],[9]. Activity concentration of ${ }^{232} \mathrm{Th}$ was determined by analyzing activity concentration of its descendant ${ }^{228} \mathrm{Ac}$ at full energy peaks of $338.42 \mathrm{keV}$, $911.16 \mathrm{keV}$ and $968.97 \mathrm{keV}$. Measurement time was typically $80000 \mathrm{~s}$.

\subsection{Radon and thoron exhalation rate measurement}

Radon exhalation rate measurements were performed using the close-chamber method [10],[11]. Measuring sample was put in the chamber of $30 \mathrm{dm}^{3}$ volume, sealed and consequently accumulation of radon concentration in chamber was measured using an active device. The accumulation of radon concentration in chamber is proportional to the exhalation rate and can be expressed as[6], [11]:

$$
C(t)=\frac{E m}{V \lambda_{\text {eff }}}\left(1-e^{-\lambda_{e f f} t}\right)+C_{0} e^{-\lambda_{e f f} t}
$$

where: $\mathrm{C}(\mathrm{t})$ is the radon concentration in time $\mathrm{t}(\mathrm{s}), \mathrm{E}$ is the radon mass exhalation rate $\left(\mathrm{Bq} \mathrm{kg}^{-1} \mathrm{~s}^{-1}\right), \mathrm{m}$ is the mass of the sample $(\mathrm{kg}), \mathrm{V}\left(\mathrm{m}^{3}\right)$ is the total volume of the measurement system including volume of the chamber, active volume of the measuring device, tubes..., $\mathrm{C}_{0}\left(\mathrm{~Bq} \mathrm{~m}^{-3}\right)$ is the radon concentration present in chamber at time when the accumulation 120 chamber is sealed and $\lambda_{\text {eff }}$ is effective radon removal probability $\left(\lambda_{\text {eff }}=\lambda+\lambda_{l}\right)$ where $\lambda$ is the radon decay constant, and $\lambda_{l}$ is leakage probability. After sealing in the chamber, samples were either measured continuously for 5-10 days or it was waited for 5-10 days before measurement started. Typical sampling times were between 1 and $4 \mathrm{~h}$.

Due to much shorter half-life of thoron $\left(\mathrm{T}_{1 / 2}=55.6\right.$ $\mathrm{s})$ compared to radon $\left(\mathrm{T}_{1 / 2}=3.82\right.$ days), for thoron exhalation rate measurements, smaller chamber of 1.5 $\mathrm{dm}^{3}$ was used. Also, sampling time (for Tn measurements was $15 \mathrm{~min}$ ) is much longer compared to the lifetime, so exponential terms in equation (1) can be neglected.

The measurement of radon concentration was performed using the RTM1688-2 device produced by SARAD $R$ GmbH company. Dependence of particle size on the exhalation rate measurement was investigated only on a few samples.

\section{RESULTS}

Activity concentration of ${ }^{226} \mathrm{Ra}$ and ${ }^{232} \mathrm{Th}$ in the analyzed building material, obtained by the gamma spectroscopic analysis is given in Table 1 . Measured activity concentration of ${ }^{226} \mathrm{Ra}$ ranges from $6.3-123$ $\mathrm{Bq} \mathrm{kg}{ }^{-1}$ and for ${ }^{232} \mathrm{Th}$ ranges $0.76-101 \mathrm{~Bq} \mathrm{~kg}$. Obtained results are comparable with previously reported results of activity concentrations ranging from $2.05-119 \mathrm{~Bq} \mathrm{~kg}^{-1}$ for ${ }^{226} \mathrm{Ra}$ and $0.179-94 \mathrm{~Bq} \mathrm{~kg}$ ${ }^{1}$ for ${ }^{232} \mathrm{Th}$ [5], [12].

Table 1. Activity concentration of ${ }^{226} \mathrm{Ra}$ and ${ }^{232} \mathrm{Th}$ and radon and thoron mass exhalation rates of various building materials

\begin{tabular}{|c|c|c|c|c|}
\hline Material & $\begin{array}{c}{ }^{226} \mathrm{Ra}^{\left[\mathrm{Bq} \mathrm{kg}^{-1}\right]}\end{array}$ & $\begin{array}{c}\mathrm{E}(222 \mathrm{Rn}) \\
{[\mu \mathrm{Bq}} \\
\left.\mathrm{kg}^{-1} \mathrm{~s}^{-1}\right]\end{array}$ & $\begin{array}{c}{ }^{232} \mathrm{Th} \\
{\left[\mathrm{Bq} \mathrm{kg}^{-1}\right]}\end{array}$ & $\begin{array}{c}\mathrm{E}\left({ }^{220} \mathrm{Rn}\right) \\
{[\mathrm{mBq}} \\
\left.\mathrm{kg}^{-1} \mathrm{~s}^{-1}\right]\end{array}$ \\
\hline $\begin{array}{l}\text { Travertine } \\
\text { (N. Banja) }\end{array}$ & $568 \pm 22$ & $361 \pm 7$ & $7.6 \pm 1.0$ & $15.3 \pm 3.1$ \\
\hline $\begin{array}{c}\text { Facade } \\
\text { brick }\end{array}$ & $117 \pm 7$ & $3.7 \pm 1.5$ & $56 \pm 4$ & $3.9 \pm 1.4$ \\
\hline $\begin{array}{l}\text { Thermal } \\
\text { block }\end{array}$ & $55^{ \pm 5}$ & $30.2 \pm 2.7$ & $7.4 \pm 1.0$ & $8.6 \pm 2.3$ \\
\hline $\begin{array}{l}\text { Natural } \\
\text { stone }\end{array}$ & $67 \pm 4$ & $70.0 \pm 6.0$ & $56 \pm 4$ & $45.0 \pm 4.9$ \\
\hline Brick block & $91 \pm 6$ & $12.9 \pm 0.9$ & $64 \pm 5$ & $15 \cdot 3 \pm 2.5$ \\
\hline Brick & $101 \pm 6$ & $4.7 \pm 3.4$ & $52 \pm 4$ & $6.2 \pm 0.6$ \\
\hline $\begin{array}{c}\text { Concrete } \\
\text { block }\end{array}$ & $51 \pm 3$ & $13.6 \pm 2.5$ & $13.7 \pm 1.2$ & $9.8 \pm 1.8$ \\
\hline $\begin{array}{l}\text { Block with } \\
\text { styrofoam }\end{array}$ & $123 \pm 7$ & $23.7 \pm 2.3$ & $17.6 \pm 1.5$ & $14.6 \pm 3.4$ \\
\hline Marble & $6.3 \pm 0.6$ & $2.2 \pm 1.2$ & $0.76 \pm 0.19$ & $<0.3$ \\
\hline Granite & $40 \pm 4$ & $1.6 \pm 0.2$ & $101 \pm 7$ & $8.2 \pm 0.4$ \\
\hline
\end{tabular}

A radon build-up in the accumulation chamber, due to radon exhalation from travertine sample, measured with $1 \mathrm{~h}$ sampling period is shown in Figure 1.

Thus obtained results were fitted using the radon exhalation equation (1) in which radon mass exhalation rate, effective decay constant and initial radon concentration were kept as free parameters. 
D. Avramović et al., Radon exhalation rate of some building materials..., RAD Conf. Proc., vol. 3, 2018, 119-122

From the fitted effective decay constant of $\lambda_{\text {eff }}=$ (107.5 \pm 4.9$) 10^{-4} \mathrm{~h}^{-1}$, knowing that $\lambda_{\text {eff }}=\lambda+\lambda_{l}$, it can be concluded that there is a certain leakage of the accumulation chamber which is determined to be $\lambda_{l}=$ $8.7 \times 10^{-7} \mathrm{~s}^{-1}$. Determination of leakage was important for measurements in which radon buildup was not continuously measured, but after a certain period of time. In that case, in equation 1 , the effective decay constant that includes leakage was used.

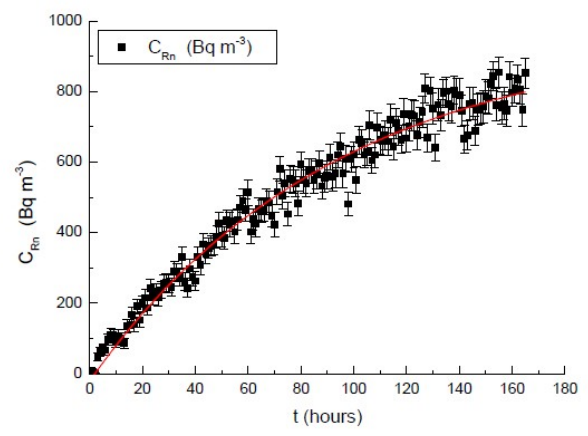

Figure 1. A buildup of radon in accumulation chamber during 7 days measured for travertine sample

Due to a small leakage probability, much smaller than a thoron decay constant, leakage in the case of thoron exhalation rate measurements was neglected. The results of the radon and thoron exhalation rate measurements for different building materials are presented in Table 1.

The radon exhalation rate ranges from 1.6 to 70 $\mu \mathrm{Bq} \mathrm{kg}{ }^{-1} \mathrm{~s}^{-1}$ (with travertine up to $361 \mu \mathrm{Bq} \mathrm{kg} \mathrm{kg}^{-1} \mathrm{~s}^{-1}$ ) which agrees with previous measurements. [5] There is no correlation between ${ }^{226} \mathrm{Ra}$ activity concentration and radon exhalation rate $\left(\mathrm{R}^{2}=0.05\right)$

The thoron exhalation rate ranges from less thano.3 to $45 \mathrm{mBq} \mathrm{kg}{ }^{-1} \mathrm{~s}^{-1}$. Obtained data agrees with previously reported results of the exhalation rate. It is interesting to notice that in the case of thoron exhalation rate as well there is no correlation with activity concentration of ${ }^{232} \mathrm{Th}$.

In Figure 2, dependence of radon and thoron exhalation rates on the particle size, for four groups of samples: 1.) $2.1-1.6 \mathrm{~mm}, 2$.) $1.6-1.2 \mathrm{~mm}, 3$.) $1.2-$ $0.5 \mathrm{~mm}$ i 4.) less than $0.5 \mathrm{~mm}$ is shown. Samples with the highest measured radon or thoron exhalation rate, that is, travertine and natural stone, were investigated.

From Figure 2 one can observe that radon exhalation rate increases with a decrease of the particle size. This is expected behavior since the smaller the particle size, the higher the probability that ${ }^{226} \mathrm{Ra}$ atom will decay close to the surface of the particle leading to the higher probability of the ${ }^{222} \mathrm{Rn}$ emanation from that grain. On the other side, statistically there is no change in the thoron exhalation rate as a function of particle size. This effect might not be visible in the case of thoron due to much shorter half-live and therefore two orders of magnitude shorter diffusion length of thoron. The effect might be visible for much smaller particle sizes.

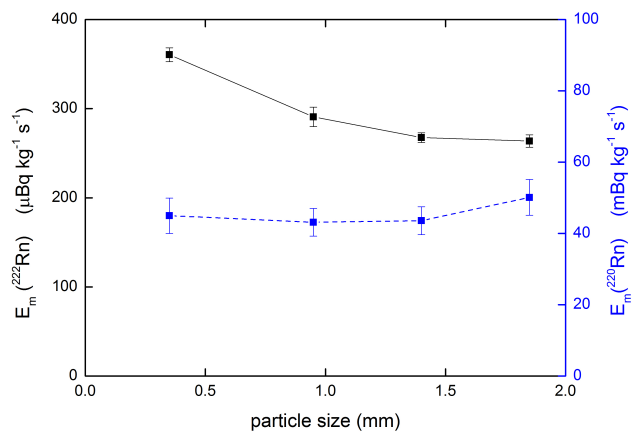

Figure 2. ${ }^{222} \mathrm{Rn}$ (black solid line) and ${ }^{220} \mathrm{Rn}$ (blue dash line) exhalation rate as a function of 4 different particle sizes: 1 ) $2.1-1.6 \mathrm{~mm}, 2) 1.6-1.2 \mathrm{~mm}, 3) 1.2-0.5 \mathrm{~mm}$ and 4) $<0.5$ $\mathrm{mm}$.

Another dependence investigated for the same samples (travertine and natural stone) was exhalation rate as a function of moisture content. Graphical representation of this dependence is shown in Figure 3 .

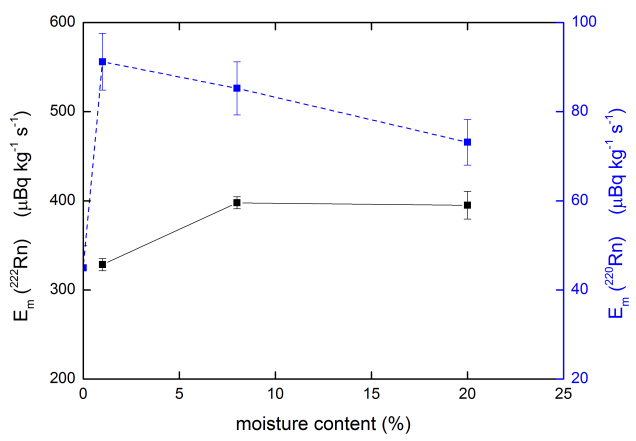

Figure $3 .{ }^{222} \mathrm{Rn}$ (black solid line) and ${ }^{220} \mathrm{Rn}$ (blue dash line) exhalation rate as a function of moisture content

An increase in exhalation rate for wet sample with respect to the dry one was observed. This observation goes along with our understanding of the emanation process. Namely, when the pores within the crystal particles are wet, the range of emanated radon atom will be reduced compared to the dry environment, reducing therefore the probability of radon atom hitting adjacent particle and being trapped in that particle [13]. With adding more moisture, the radon exhalation rate tends to decrease which could be explained by the saturation of sample with water. Again, this effect looks more sensitive for thoron.

\section{CONCLUSION}

In the paper, radon and thoron exhalation rate of 10 building materials most common in Serbia were 
D. Avramović et al., Radon exhalation rate of some building materials..., RAD Conf. Proc., vol. 3, 2018, 119-122

investigated. The absence of correlation between the results of radon/thoron exhalation rates and ${ }^{226} \mathrm{Ra}$ and ${ }^{232} \mathrm{Th}$ activity concentration was observed. This observation indicates that one should measure the exhalation of rate of building materials since its value could not deduced from the ${ }^{226} \mathrm{Ra}$ and ${ }^{232} \mathrm{Th}$ activity concentration. The radon exhalation rate increases with a decrease of particle size, indicating that it is better to have the material with larger particle size. On the other side, this effect is not visible for thoron, perhaps due to a much shorter half-life. With the investigation of the effect of moisture size as a function of moisture content, it was found that exhalation was larger for wet samples compared to dry ones. An increase in exhalation rate was about $20 \%$ in the case of radon and around $60 \%$ for thoron , indicating therefore that moisture content should be considered when making dose estimation due to exposure to radon.

Acknowledgements: The authors acknowledge the support of the Ministry of Education, Science and Technological Development of the Republic of Serbia [P171018, P171007].

\section{REFERENCES}

1. Sources and Effects of Ionizing Radiation, vol. 1, Annex B, UNSCEAR 2000 Report to the General Assembly with Scientific Annexes, UNSCEAR, New York (NY), USA, 2000.

Retrieved from: http://www.unscear.org/docs/publica tions/2000/UNSCEAR 2000_Annex-B.pdf; Retrieved on: Nov. 20, 2018

2. Handbook on Indoor Radon: A public health perspective, WHO, Geneva, Switzerland, 2009. Retrieved from: http://apps.who.int/iris/bitstream/ha ndle/10665/44149/9789241547673 eng.pdf?sequenc $\mathrm{e}=1$;

Retrieved on: Nov. 20, 2018

3. Who guidelines for indoor air quality: selected pollutants, WHO Regional Office for Europe, Copenhagen, Denmark, 2010. Retrieved from: http://www.euro.who.int/ data/ass ets/pdf file/0009/128169/e94535.pdf; Retrieved on: Nov. 20, 2018

4. I. Yarmoshenko, A. Vasilyev, A. Onishchenko, S. Kiselev, M. Zhukovsky, "Indoor radon problem in energy efficient multi-storey buildings," Radiat. Prot. Dosim. vol. 160, no. 1-3, pp. 53 - 56, Jul. 2014.
DOI: $10.1093 / \mathrm{rpd} / \mathrm{ncu} 110$

PMid: 24723188

5. P. Ujić et al., "Internal exposure from building materials exhaling $222 \mathrm{Rn}$ and $220 \mathrm{Rn}$ as compared to external exposure due to their natural radioactivity content," Appl. Radiat. Isot., vol. 68, no. 1, pp. $201-206$, Jan. 2010.

DOI: 10.1016/j.apradiso.2009.10.003 PMid: 19880324

6. P. Ujić, I. Čeliković, A. Kandić, Z. Žunić, "Standardization and difficulties of the thoron exhalation rate measurements using an accumulation chamber," Radiat. Meas., vol. 43, no. 8 , pp. 1396 - 1401, Sep. 2008.

DOI: 10.1016/j.radmeas.2008.03.003

7. A. Awhida et al., "Novel method of measurement of radon exhalation from building materials," J. Environ. Radiat. vol. 164, pp. 337 - 343, Nov. 2016.

DOI: 10.1016/j.jenvrad.2016.08.009 PMid: 27552657

8. G. Jia, J. Jia, "Determination of radium isotopes in environmental samples by gamma spectrometry, liquid scintillation counting and alpha spectrometry: a review of analytical methodology," J. Environ. Radiat. vol. 106, pp. 98 - 119, 2012. DOI: 10.1016/j.jenvrad.2011.12.003

9. B. Šešlak et al., "Determination of $210 \mathrm{~Pb}$ by direct gamma-ray spectrometry, beta counting via $210 \mathrm{Bi}$ and alpha particle spectrometry vi 210 Po in coal, slag and ash samples from thermal power plant," $J$. Radioanal. Nucl. Chem. vol. 311, no. 1, pp. 719 - 726, Jan. 2017. DOI: 10.1007/s10967-016-5028-6

10. F. A. Abu-Jarad, "Application of nuclear track detectors for radon related measurements," Nucl. Tracks Radiat. Meas. vol. 15, no. 1-4, pp. 525 - 534, 1988.

DOI: 10.1016/1359-0189(88)90195-1

11. N. P. Petropoulos, M. J. Anagnostakis, S. E. Simopoulos, "Building materials radon exhalation rate: ERRICCA intercomparison exercise results," Sci. Total Environ. vol. 272, no. 1-3, pp. $109-118,2001$. DOI: 10.1016/Soo48-9697(01)00674-X

12. D. Krstić, D. Nikezić, N. Stevanović, D. Vučić, "Radioactivity of some domestic and imported building materials from South Eastern Europe," Radiat. Meas. vol. 42, pp. 1731 - 1736, Nov. 2007. DOI: 10.1016/j.radmeas.2007.09.001

13. S. Durrani, R. Ilić, Radon measurment by Etched Track Detectors, Singapore, Signapore: World Scientific Publishing Co.,Pte., 1997.

DOI: $10.1142 / 3106$ 